\title{
The use of animated agents in e-learning environments: an exploratory, interpretive case study
}

\author{
A. Kamil Mahmood and Elaine Ferneley* \\ University of Salford, UK
}

There is increasing interest in the use of animated agents in e-learning environments. However, empirical investigations of their use in online education are limited. Our aim is to provide an empirically based framework for the development and evaluation of animated agents in e-learning environments. Findings suggest a number of challenges, including the multiple dialogue models that animated agents will need to accommodate, the diverse range of roles that pedagogical animated agents can usefully support, the dichotomous relationship that emerges between these roles and that of the lecturer, and student perception of the degree of autonomy that can be afforded to animated agents.

\section{Introduction}

A new educational paradigm is emerging: face-to-face interaction with intelligent pedagogical animated agents in interactive learning environments that are capable of performing tasks and achieving goals individually and in collaboration with human and non-human agents. Currently, significant work has been undertaken on incorporating conversational behaviours of emotion, personality, conversational performatives and functions into such agents (Cassell et al., 2000; Ruttkay \& Pelachaud, 2004). However, little empirical work exists on their utility from the end user perspective. That which does exist, while insightful, focuses on the expressiveness of animated agents rather than the functionality that end users may require from them (Lester et al., 1997). Using an interpretive case study approach, this research has developed a framework for pedagogical animated agent evaluation that focuses on end-user-defined functional requirements. The research participants were early adopters of animated agent technologies within e-learning environments at a Malaysian university.

\footnotetext{
* Corresponding author. Informatics Research Institute, 5th Floor, Maxwell Building, University of Salford, The Crescent, Salford, Manchester M5 4WT, UK. Email: e.ferneley@salford.ac.uk
} 


\section{Background}

There is a growing body of literature relating to e-learning including research on the adoption of courseware (Russell, 1999), learner experiences with e-learning (Hara \& Kling, 1999; Johnson et al., 2000a) and the comparison of the critical attributes of traditional and e-learning environments (Blignauta \& Trollipa, 2003). Increasingly sophisticated features are being conceptualised and incorporated in e-learning systems such as intelligent agents (Lester et al., 2000; Schroeder, 2002), adaptive hypermedia (Ng et al., 2002) and game-based learning (Foreman, 2004) that aim to make e-learning friendly and engaging for both instructors and learners.

The inclusion of intelligent agent technology in e-learning environments has been of growing interest (Conole, 2002; Logan et al., 2002; Songa et al., 2004). Intelligent agents are computer programs that can act autonomously and perform tasks intelligently with consideration given to context and user preferences. They support the user in carrying out computerised tasks such as information searching, meeting scheduling or online purchasing (Maes, 1994). Advances in computer graphics have made the embodiment of intelligent agents (known as animated agents) possible (Schroeder, 2002) and e-learning researchers have proposed the utilisation of animated agents to reduce the overheads involved in delivering online education, to facilitate dynamic monitoring of course activities and delegation of certain instructor tasks to pedagogical animated agents (Johnson et al., 2000b; Conole, 2002; Jafari, 2002; Songa et al., 2004). The expectation is that learners will be able to interact visually with pedagogical animated agents who will be able to exhibit emotive behaviour and expressions and simulate continuous instructor presence in e-learning environments. This notion is in line with the futuristic vision of the Peripatetic Electronic Teacher, as coined by Squires (1999), the freelance educator providing education virtually on demand with their routine tasks supported or delivered by agent-based technology that will be required to operate in four key roles or 'presences': as a pedagogical presence, in a managerial role as a professional (usually in some peer group setting) or in a commercial role as a personal marketeer. In the 1990s animated agents were developed to support students in the use of educational programs; for example, Herman the Bug (Lester et al., 1999), Steve-Soar Training Expert for Virtual Environments (Rickel \& Johnson, 1999) and Adele-Agent for Distance Learning (Shaw et al., 1999). However, there is now a sense of urgency in identifying how to incorporate pedagogical agent technology appropriately in e-learning environments.

While a utopian vision may exist of learners interacting seamlessly with pedagogical animated agents, in practice animation can be irritating and empirical investigations have revealed diverse results in a continuum from animated agents being helpful to them being distracting and hampering the learning process (Dehn \& Mulken, 2000; Ruttkay \& Pelachaud, 2004). Additionally, there are concerns regarding their pedagogical value, with no clear evidence that they can enhance communication or understanding (Dehn, 2000; Moundridou \& Virvou, 2002). Hence their contribution to the efficiency and effectiveness of learning continues to be an open research agenda. 
Therefore, this paper can be seen as a response to the question: 'what kind of animated agent used in what kind of domain influences what aspects of the user's attitudes or performance?' (Dehn \& Mulken, 2000, p. 19). It will involve examining the application of pedagogical animated agents in e-learning environments. Since the question has multiple components, this paper investigates only the final portion, providing additional insights into learners' perceptions of the utility of animated agents in e-learning environments. The key result of the research is a conceptual design and evaluation framework for the incorporation of animated agents in e-learning environments.

\section{Methodology}

Examining the use of pedagogical animated agents requires investigation from multiple stakeholder perspectives (e.g. lecturers, undergraduate and postgraduate students) and an understanding of the social and contextual relationships that influence the stakeholders - there can be no single explanation of success. Our epistemological assumptions are that no individual account of social reality can be proven correct. Therefore, as the fundamental nature of this study is concerned with interpreting human action and perceptions, the researchers drew on an interpretive and qualitative research tradition in order to explore and understand the perspectives of the various stakeholders and the historical and socially situated contexts in which they reside (Walsham, 1995; Klein \& Myers, 1999). The usual approach to gaining such understanding (or 'rich insight'), particularly where the phenomena cannot be studied outside of the context in which it occurs, is an observation-based case study approach (Walsham, 1993; Yin, 1994).

The case study was conducted in the Information Systems department at a private university in Malaysia. The department has made extensive use of e-learning facilities, offering as part of its degree programme full online modules and blended learning modules since 2000. Since the adoption of e-learning facilities, staff have incorporated a variety of animated agents into their online materials, including animated instructional agents developed using Microsoft Agent ${ }^{\text {TM }}$ (Microsoft, 2006), the demonstration and problem-solving animated agents Steve and Adele (Rickel \& Johnson, 1999; Shaw et al., 1999) and information search and retrieval agents such as Gossip (Tryllian, 2006). Case study data were collected by the first author who is an academic member of staff at the institution and a native Malaysian, speaking the language of the participants. This 'insider' perspective expedited data collection and enabled a deeper understanding of the issues raised. The research design process was executed in phases (Yin, 2003).

\section{First phase: planning and preparation}

In undertaking qualitative research, there is more than one way in which it may be performed, as Markus underlined: 
If we who claim to understand qualitative research argue that there is only one right way to do it, we are deliberately blinding ourselves to many interesting and important research questions and phenomena. (1997, p. 15)

In this study the planning and preparation phase began with a detailed literature review. Three seed research questions were explored:

- What roles can animated agents effectively assume in e-learning environments?

- When, how and for whom would those roles be initiated?

- Do social and cultural factors influence the interaction between the users and animated agents?

A conceptual framework was developed, founded on the research questions (Miles \& Huberman, 1994). This framework acted as the stimuli for data collection. Briefly the framework consisted of the following:

- Learner characteristics - including, learning style (visual, auditory or kinaesthetic; Sabry \& Baldwin, 2003); system experience (Holscherl \& Strubel, 2000), prior knowledge and spatial ability (Mayer \& Gallini, 1990) and occupational experience (Durling et al., 1996).

- Technology - the various technologies and mediums used to deliver and communicate with the learners, including speech, text, sound and animated agent expression.

- Learning environment-physical attributes including monitor size, microphone and speaker position and room layout; and virtual attributes including look and feel of the applications, courseware content and structure.

- Culture - the users' enacted system of beliefs, symbols and behaviours; and collective programming of the mind such as the learning of ideas, habits, attitudes, customs and traditions (Hofstede, 1991).

\section{Second phase: fieldwork}

Data were collected over a 12-month period using participant observation and individual and group interviews. All participants were from the Malaysian university's Information Systems department. Twenty-six interviewees were involved in 21 separate sessions: six individual lecturer interviews, four individual postgraduate interviews, one group postgraduate interview (two participants), eight individual undergraduate interviews and two group undergraduate interviews (three participants in each group interview). While the majority of interviews were individual, three small group interview sessions were undertaken with students to explore whether different issues emerged, although no significantly different issues did. Interviews began with more generic questioning allowing users to express their opinions on the use of pedagogical animated agents before moving to more specific issues to ensure that data from each interview covered similar areas thus allowing cross-respondent comparison. Data collection ceased at the point of data saturation (Miles \& Huberman, 1994). Simulated propositions were presented to the interviewees in the 
form of a series of small video clips from the Star Trek television series that showed possible future applications for animated agents. The aim was to allow discussion of possible future scenarios but to 'bound' the discussion and give some direction to respondents to allow cross-respondent comparison. The videos included examples of animated agents on Star Trek's holodeck and embedded agents in Star Trek's engineering department.

The sampling approach for choosing the interviewees was driven by the emerging themes. The aim was not to capture the representativeness of the population, but rather to continuously solicit and analyse the 'hows' of meaning and the 'whats' of interviewees' experiences until the findings were either being reinforced or emergent issues were saturated. During both the observation sessions and interviews the researcher took field notes, highlighting potential emergent themes. All interviews were video-recorded and conducted in the language and style of expression that was most convenient for the interviewees to convey meaning, which at times was a mix of English and Malay. Interviews lasted between 50 minutes and 2 hours 20 minutes. Table 1 provides an overview of the structure, format and issues covered in the interviews, although this is only indicative as an open rather than closed questioning style was used.

\section{Third and fourth phases: summarising and aggregating the data}

Full transcripts were made of all interview sessions, and summaries were made of all observational sessions. Using an inductive analytical approach an initial coding scheme derived from the initial, literature-based, conceptual framework was further explored and refined by application of the case study data, providing a 'behavioural description' of the use of pedagogical animated agents (Miles \& Huberman, 1994). As coding progressed a number of themes began to emerge; namely, the various roles that pedagogical animated agents could assume, the various effects that pedagogical animated agents have on users and context and cultural factors that may influence user interaction. Because qualitative data analysis is an open and iterative process, applying the initial coding scheme to the case studies resulted in the emergence or induction of a richer coding set as the initial codes were 'extended', 'filled in', 'bridged' and 'surfaced' (Lincoln \& Guba, 1985). For illustration, the 'roles' cluster evolved to include a set of subclusters including the roles of personal assistant, demonstrator, counsellor and peer (see also Table 2). Validation of the coding scheme was undertaken by gaining feedback from interviewees and the co-researcher and by applying the principles of the hermeneutic cycle (Klein \& Myers, 1999). Qualitative data analysis software was used to assist in the coding process. These subclusters are supported by various logical chains of evidence matrices. For illustration, an extract from the role-ordered matrix that shows a subset of the emergent roles is presented in Table 2. The role-order matrix was created by extracting the various requirements and issues that each type of respondent identified as factors in the use of pedagogical animated agents. For illustration and due to space limitations only one or two requirements/issues are presented for each cell within the role-order matrix. 


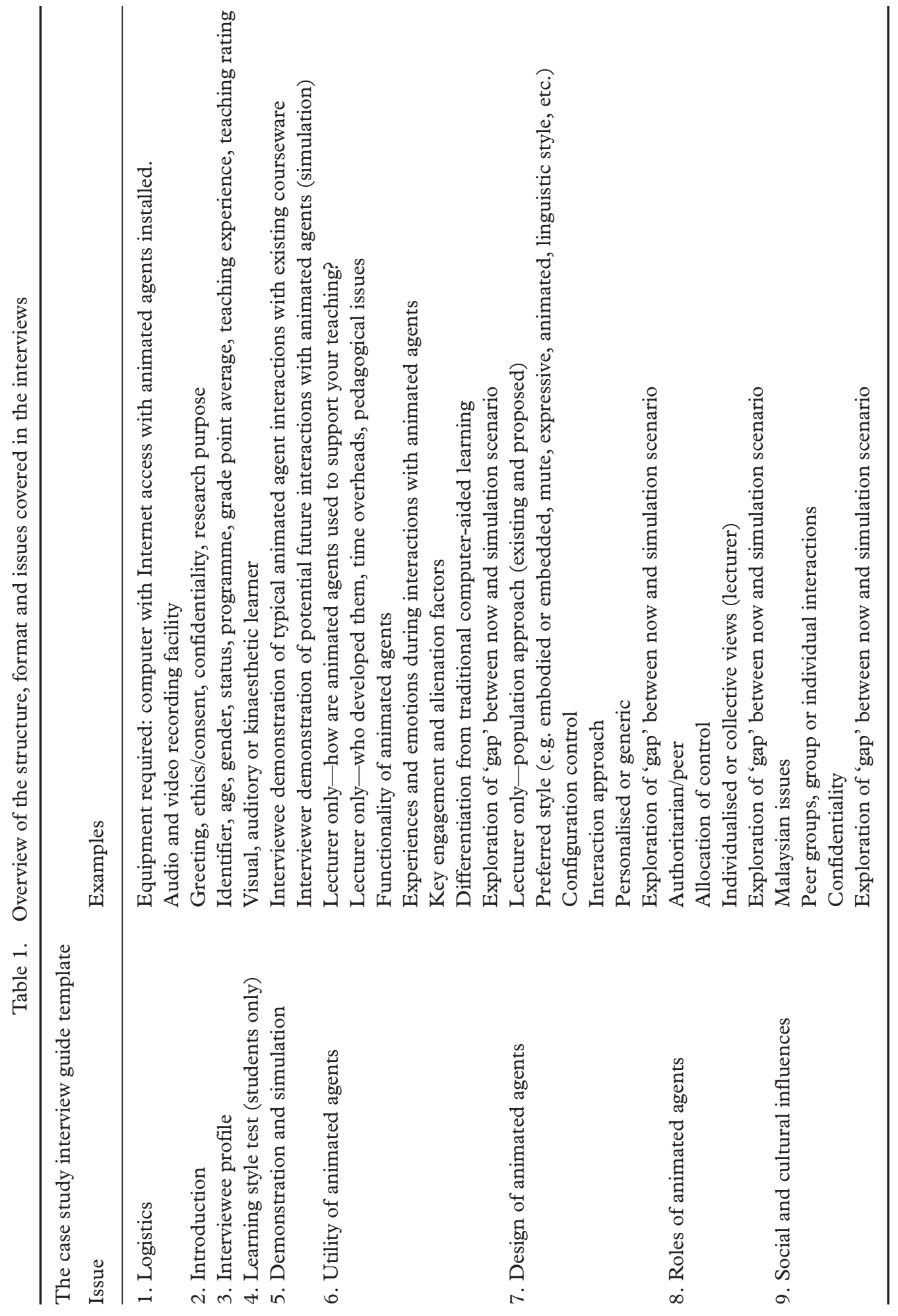




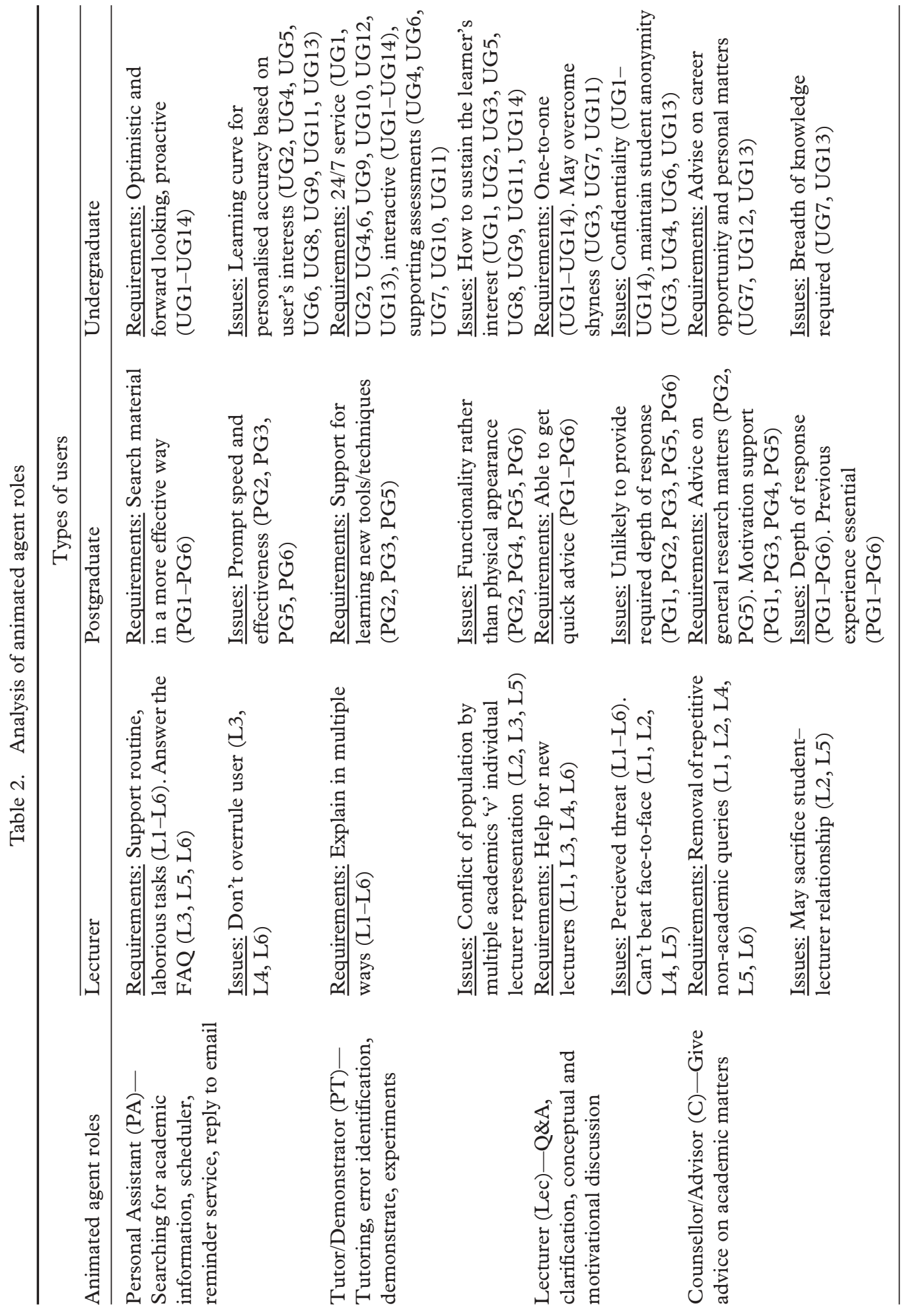




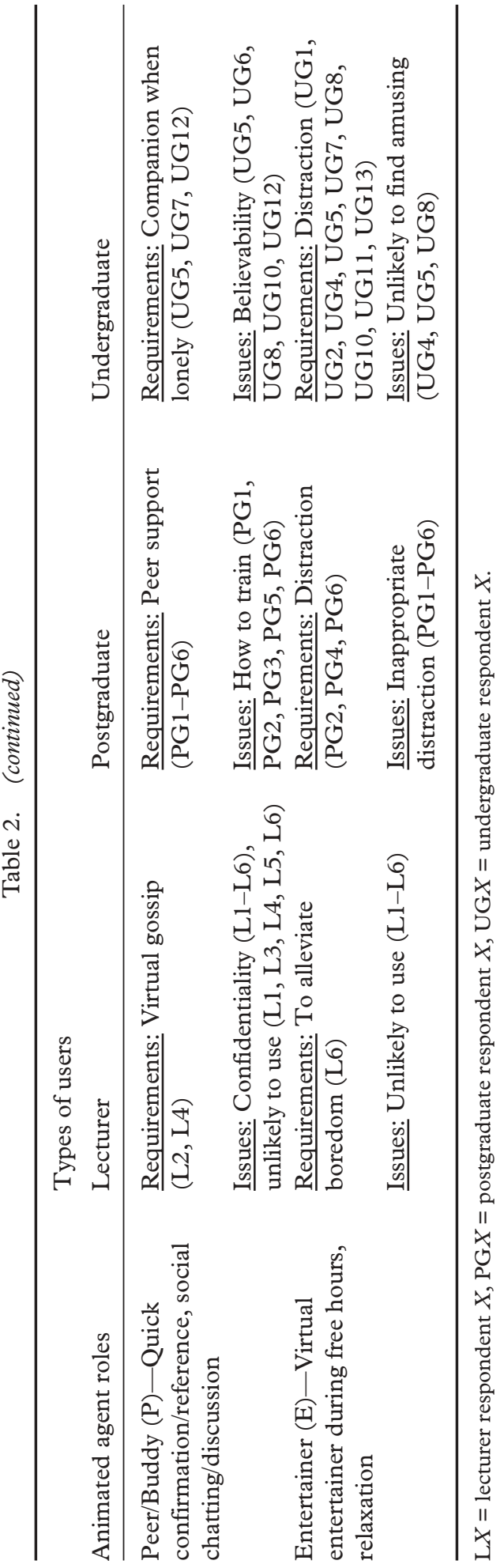




\section{Results}

The key findings abstracted from the matrices were:

\section{Animated agent roles}

The data analysis revealed a range of potential roles for animated agents including personal tutor, personal assistant, mentor, academic counsellor, lecturer, entertainer, buddy and peer. The instantiation of these roles was viewed very differently by academic and student respondents. Considering Squire's (1999, p. 54) four 'presence' domains, broadly, students focused on animated agents providing a pedagogical presence, while academics expected animated agents to assume a managerial stance. Neither user group considered Squires's professional or commercial perspectivesfor example, animated agents as representatives at academic meetings or animated agents in some form of marketing or sales role.

Lecture perspective. Lecturers were willing to, and many did, delegate laborious, routine 'low-risk' tasks to animated agents, including searching for academic and administrative information, managing appointments and replying to non-crucial e-mails. One of the lecturers stated:

If the agents can do half of my routine tasks, that would be nice ... as an academic, I can spend that valuable spare time for more productive activities. I don't mind if those routine tasks are handled by agents.

However, they identified the major barrier to adoption included the time overhead required to gain familiarity with the technology, the training curve required by agent technologies and past unsatisfactory results from using agents

For more advanced roles it was recognised that a more constructivist, learnercentred approach to education would benefit students and that pedagogical animated agents can operate as a 'guide-on-the-side'. For example, animated agents explaining subject matter in an alternative way, rephrasing the material and providing alternative diagrams, animations and texts to support the student's learning style had been trialled and were discussed. A lecturer stated:

The agents should be able to explain in different ways ... the agent should be able to capture, rephrase and reinforce answers or questions.

Concern was expressed that learners do not trust the technology, that their attention may wane, that animated agents may tarnish the image of the lecturer, especially when the agents have a strong association with the lecturer, that possible negative effects on lecturer-student relationships may ensue and that animated agents may pose a potential threat to teaching careers. Additionally, interviewees were concerned that animated agents were a passing fad and they had neither the time nor the ability to change their teaching styles to fully incorporate them into their online courses, especially if animated agents were required to present an alternative pedagogical approach to the material being delivered. 
Student perspective. Postgraduates were not interested in animated agent aesthetics. For example:

If it fails to deliver I am not going to use it. Look is secondary—it is the practicality, speed and quality of response that count.

They focused on the possibility of advanced animated agent roles such as advisor or mentor, as stated by one respondent, and typical of others:

My current problem as research student is how to understand what I read ... interactive software could help, maybe in terms of visualisations instead of just reading the literature.

Potential animated agent roles were advanced with context specific requirements that are at the boundaries of current technology. They proposed a mediating role of 'team buddy', providing support for groups of research postgraduates and stimulating collaborative research or learning.

Undergraduates focused on more informal animated agent roles to help them overcome feelings such as shyness and inferiority, by engaging in a more open, informal environment, as stated by one respondent:

Agents can actually help the student in a 'virtual way', there is no connection between lecturer and student, ... can get the answers or help outside the classroom.

Undergraduates also emphasised the need for 24-hour service, for repeated one-toone interaction on the same topic within a confidential environment and interaction at the intellectual level of the undergraduate - a personalised user profile. This concept of service and personalisation was linked to interest retention, and analogies between gaming software and e-learning environments were repeatedly made; for example:

I think if the animated software agents play their roles right, they can help to make the courseware as interesting as the games software, and ... retain the interest of the learner. For example, we can revise the assignments to look more like games software rather than like academic problems.

Despite undergraduates' enthusiasm for animated agents there was concern that such technology could not sustain high motivation and engagement in learning. Such motivational activity was regarded as a human process.

\section{Social and cultural influences}

As social and cultural influences are an intrinsic part of learning, the issue of customisability that allows factors such as language, looks and communication styles to be incorporated into an animated agents was raised. Culturally, the Malaysian respondents focused on the inclusion of Asian characteristics into animated agent designs for reasons of 'national pride'. Also, with respect to the Malaysian context, there was a reluctance to express dissent, to query or be critical of academic authority. The respondents saw the introduction of pedagogical animated agents as an opportunity to act in a less reserved fashion and adopt a more questioning, critical style of interaction. However, despite cultural factors being mentioned, it was 
repeatedly stated that quality of interaction with animated agents was more relevant than cultural identity.

Socially, interviewees focused on animated agents being able to personalise their interaction with learners dependent on a user's profile, considering attributes such as past interactions and learner style with the aim of improving interaction and simplifying steps towards understanding the subject under study. Interviewees also expressed a desire for animated agents that used informal, friendly language, communicating at the intellectual level of the user and taking the role of tutor, counsellor or buddy rather than the more authoritarian lecturer stance. The role of entertainer was also mentioned-an animated agent that can identify when the user is bored, can distract or even 'crack an academic joke': the overarching desire was for a high level of context dependent personalisation.

\section{Animated agent design framework}

The multiple academic and student perspectives were summarised in a framework for animated agent design in e-learning environments. Figure 1 illustrates this framework graphically using the qualitative data analysis NVivo Modeller software.

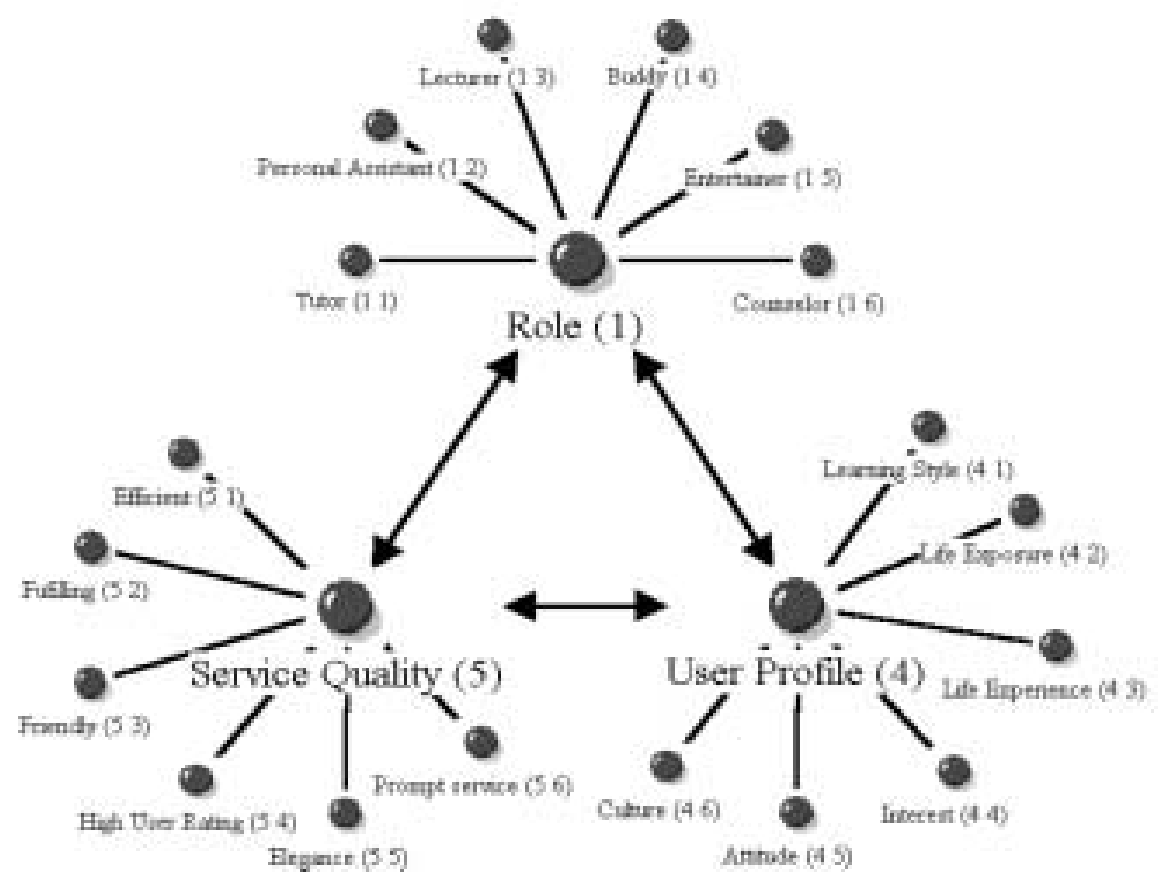

Figure 1. Animated agent design framework 


\section{Discussion}

Pedagogical animated agents have many similarities with other work in intelligent tutoring systems and interactive e-learning environments including reasoning capabilities, user profiling, mechanisms for evolving with the user, pedagogical approach and the maintenance of a logical dialogue with the user (Cassell et al., 2000; Ruttkay $\&$ Pelachaud, 2004). However, previous research has drawn on empirical studies in other domains to identify the utility of pedagogical animated agents in e-learning environments. This in-depth case study research has been conducted with experienced e-learning users who had used pedagogical animated agents previously to develop a framework of key requirements for pedagogical animated agents in e-learning environments.

\section{Animated agent roles}

A range of roles were identified that a pedagogical animated agent could assume: Tutor, Personal Assistant, Lecturer, Buddy, Entertainer and Counsellor. As with any autonomous agent, the agent must be able to react dynamically with its environment while maintaining a coherent dialogue with the user. The possibility of assuming multiple roles and, at the same time being embodied, raises particular challenges for the animated agent designer.

Dialogue context. The instructional goals may vary dependent on the animated agent's role and the stage in the dialogue. A dialogue model is required that considers both the ultimate and immediate conversational goals. In a dynamic environment the design of the animated agent to allow seamless transfer between roles while maintaining coherence will be particularly challenging. The designer may consider alternative embodiments allowing a range of non-verbal behaviours depending on role rather than attempting to combine roles into a single animated agent.

Visual context. A key difficulty in animated agent design is the design of suitable non-verbal behaviours; for example, appropriate changes in facial expression. In this study respondents repeatedly stated that the visual representation was secondary to service quality, and therefore e-learning designers may be advised to utilise simplistic embodiments until the animated agent designers have further addressed issues of believability.

Pedagogical context. Dependent on the animated agent's role, the pedagogical intent will vary. While the capture of appropriate dialogue to support the more formal Lecturer or Tutor roles may be time consuming, it is unlikely that there would be ambiguity in meaning. However, if alternative pedagogical approaches and peer-type support is to be included then there is a key question regarding how the appropriate, alternative pedagogical structures will be captured. In order to support multiple roles, 
multiple pedagogical perspectives (presumably captured from multiple academics) would be required. This study highlighted a number of concerns from academics regarding engaging with such technology. If said technology presents pedagogical views that do not concur with the academic user's perspective, the likelihood of adoption is significantly reduced. There is a dichotomy here between the utility of providing multiple animated agent roles and the likelihood of adoption by academics.

\section{Animated agent service quality and usefulness}

Unsurprisingly the service quality and usefulness of animated agents emerged as a key theme, specifically as respondents had previously experienced animated agents that were distracting and annoying.

Presence context. Animated agents as a distraction or annoyance emerged, particularly if inappropriate behaviours were assigned to them. The respondents, both educators and students, emphasised the desire to be in control of the animated agents, to be able to determine when to engage with them. Yet, from the educator and student perspectives the desire for control was pedagogically contradictory. Lecturers expressed a desire for highly controlled agents that they could program in detail to structure the learning process. Students similarly wished to control agent interaction and determine the role an animated agent should adopt dependent on context (e.g. peer, buddy or tutor). A key challenge for future designers is how to accommodate these two views of where control should be located.

Profile context. For multiple, context-dependent roles and behaviours to occur a user profiling approach would appear appropriate. A user's learning style, career history, interests, attitudes and culture are all unique making their learning experience a personal journey. To incorporate such attributes into a personalised agent has long been an aim in agent design (Maes, 1994) and is a vision that has been incorporated into Squires' notion of the Peripatetic Electronic Teacher (Squires, 1999). However, this utopian vision is still a long way from realisation, and pedagogical animated agent developers need to face the challenge of integrating user profiling and agent technology while both fields are still in their infancy.

\section{Conclusions}

Learners are being confronted with an ever-increasing quantity of information while at the same time the distance between themselves and their educator becomes either physically or conceptually greater. This 'gap' has been partially filled by e-learning environments. More recent research has moved towards the use of pedagogical animated agents, focusing on conversational behaviours and design features (Cassell et al., 2000; Johnson et al., 2000b; Ruttkay \& Pelachaud, 2004). However, in order to achieve Squires's futuristic vision of the Peripatetic Electronic Teacher, a clearer 
understanding of end users' expectations of pedagogical animated agents is required (Johnson et al., 2000a; Conole, 2002; Logan et al., 2002).

The research presented here has employed an in-depth interpretive case study approach to explore the issues surrounding the use of pedagogical animated agents in e-learning environments. The case study site has employed animated agents and elearning as part of their educational delivery strategy for over five years. While the latest research on animated agents in e-learning environments has focused on design issues of believability and deictic behaviour, the participants in this research were more concerned with exploiting the classic characteristics of intelligent agents, such as autonomy, proactiveness and social ability. The participants already had experience of pedagogical animated agents and repeatedly expressed concern that interface issues did not dominate to the expense of functional requirements. The research identified three key themes for pedagogical animated agent development: the instantiation of multiple roles, quality of service and a user-profile-based approach. Taking these three themes a number of issues arise:

- Potential conflicting roles of the various animated agents. As a learner begins to interact with multiple animated agents, how can a consistent dialogue model be maintained?

- Population of animated agents. In order to provide the quality of service, multiple experts may be required to work collaboratively to populate the various animated agent roles; for example, to provide alternative pedagogical models on specific topics. This has significant set-up cost implications. Dichotomously, lecturers wished to maintain personalised animated agents that presented their material in a particular format and style.

- Quality assurance procedures. If pedagogical animated agents are ultimately to be autonomous, proactive and socially agile then clearly defined quality assurance procedures need to be put in place to ensure that the pedagogical integrity of the animated agents is maintained.

- Development of user profiles including learning styles, career background and interests in order to develop a personalised presentation style. For example, in order to tailor learning to an individual's requirements it may be useful to know whether they are typically classed as a visual, auditory or kinestatic learner. Yet, how would a user profile be captured? For example, a learner will not necessarily know which learning style is most appropriate for their needs while a pedagogical animated agent will need to know how to present information to best effect dependent on the particular learner.

The issues raised highlight the speculative nature of this field and are based on a single case study. However, the case study respondents had been exposed to both elearning environments and pedagogical animated agents for some five years. While the implications suggested here might not be applicable to the individuals outside this sample (Lee \& Baskerville, 2003), the findings and suggestions, as in any case study, may be useful for further study and act as a foundation for further longitudinal research. 


\section{Acknowledgements}

The authors are greatly indebted to the two anonymous reviewers for their valuable critiques and suggestions. They would also like to thank the editor for his advice and guidance.

\section{References}

Blignauta, S. \& Trollipa, S. R. (2003) Developing a taxonomy of faculty participation in asynchronous learning environments-an exploratory investigation, Computers $\mathcal{E}$ Education, 41, 149-172.

Cassell, J., Sullivan, J., Prevost, S. \& Churchill, E. (Eds) (2000) Embodied conversational agents (Cambridge, MA, The MIT Press).

Conole, G. (2002) The evolving landscape of learning technology, Association For Learning Technology fournal, 10, 4-18.

Dehn, D. M. (2000) The impact of animated interface agents: a review of empirical research, International fournal Human-Computer Studies, 52, 1-22.

Dehn, D. M. \& Mulken, S. V. (2000) The impact of animated interface agents: a review of empirical research, International fournal of Human-Computer Studies, 52, 1-22.

Durling, D., Cross, N. \& Johnson, J. (1996) Personality and learning preferences of learners in design-related disciplines, Proceedings of the International Design and Technology Educational Research and Curriculum Development Conference (IDATER 96), Loughborough University.

Foreman, J. (2004) Game-based learning: how to delight and instruct in the 21st Century, Educause Review Quarterly, September/October, 51-66.

Hara, N. \& Kling, R. (1999) 'Students' frustrations with a Web-based distance education course', First Monday, 4. Available online at: http://www.firstmonday.org/issues/issue4_12/hara/ index.html (accessed 15 September 2004).

Hofstede, G. (1991) Cultures and organizations: software for the mind (London, McGraw Hill).

Holscherl, C. \& Strubel, G. (2000) Web search behaviour of Internet experts and newbies, Computer Networks, 33, 337-346.

Jafari, A. (2002) Conceptualising intelligent agents for teaching and learning, Educause Quarterly, 25(3), 28-34.

Johnson, S. D., Aragon, S. R., Shaik, N. \& Palma-Rivas, N. (2000a) Comparative of learner satisfaction and learning outcomes in online and face-to-face learning environments, fournal of Interactive Learning Research, 11, 24-49.

Johnson, W. L., Rickel, J. W. \& Lester, J. C. (2000b) Animated pedagogical agents: face-to-face interaction in interactive learning environments, International fournal of Artificial Intelligence in Education, 11, 47-78.

Klein, H. K. \& Myers, M. D. (1999) A set of principles for conducting and evaluating interpretive field studies in information systems, MIS Quarterly, 23, 67-94.

Lee, A. S. \& Baskerville, R. L. (2003) Generalizing generalizability in information systems research, Information Systems Research, 14, 221-243.

Lester, J. C., Converse, S. A., Kahler, S. E., Barlow, S. T., Stone, B. A. \& Bhogal, R. (1997) Proceedings of CHI'97 Human Factors in Computing Sstems, ACM, Atlanta, GA.

Lester, J. C., Stone, B. A. \& Stelling, G. D. (1999) Lifelike pedagogical agents for mixed-initiative problem solving in constructivist learning environments, User Modeling and User-Adapted Interaction, 9, 1-44.

Lester, J. C., Towns, S. G., Callaway, C. B., Voerman, J. L. \& Fitzgerald, P. J. (2000) Deictic and emotive communication in animated pedagogical agents, in: J. Cassell, J. Sullivan, S. Prevost \& E. Churchill (Eds) Emboddied conversational agents (Cambridge, MA, The MIT Press), 123-154.

Lincoln, Y. S. \& Guba, E. G. (1985) Naturalistic inquiry (Beverley Hills, CA, Sage). 
Logan, B., Fraser, M., Fielding, D., Benford, S., Greenhalgh, C. \& Herrero, P. (2002) Keeping in touch: agents reporting from collaborative virtual environments. Artificial intelligence and interactive entertainment, papers presented at the American Association for Artificial Intelligence Symposium, 2002. Technical report SS-02-01 (Menlo Park, CA, AAAI Press).

Maes, P. (1994) Agents that reduce work and information overload, Communications of the ACM, 37, 31-40.

Markus, M. L. (1997) The qualitative difference in information systems research and practice, in: A. S. Lee, J. Liebanu \& J. I. DeGross (Eds) In information systems and qualitative research (London, Chapman and Hall), 11-27.

Mayer, R. E. \& Gallini, J. K. (1990) When is an illustration worth ten thousand words?, fournal of Educational Psychology, 82, 715-726.

Microsoft (2006) Microsoft Agent. Available online at: http://www.microsoft.com/msagent/ default.asp

Miles, M. \& Huberman, A. (1994) Qualitative data analysis: an expanded sourcebook (Thousand Oaks, CA, Sage).

Moundridou, M. \& Virvou, M. (2002) Evaluating the persona effect of an interface agent in an intelligent tutoring system, fournal of Computer Assisted Learning, 18(3), 253-261.

Ng, M. H., Hall, W., Maier, P. \& Armstrong, R. (2002) The application and evaluation of adaptive hypermedia techniques in Web-based medical education, Association For Learning Technology fournal, 10, 19-40.

Rickel, J. \& Johnson, W. L. (1999) Animated agents for procedural training in virtual reality: perception, cognition and motor control, Applied Artificial Intelligence, 13, 343-382.

Russell, T. L. (1999) The no significance difference phenomenon (New Brunswick, IDECC). Available online at: http://teleeducation.nb.ca/nosignificantdifference/ (accessed 20 August 2004).

Ruttkay, Z. \& Pelachaud, C. (Eds) (2004) From brows to trust: evaluating emboddied conversational agents (Dordrecht, Kluwer Academic Publishers).

Sabry, K. \& Baldwin, L. (2003) Web-based learning interaction and learning styles, British fournal of Educational Technology, 34, 443-454.

Schroeder, R. (Ed.) (2002) The social life of avatars (London, Springer-Verlag).

Shaw, E., Johnson, W. L. \& Ganeshan, R. (1999) Pedagogical agents on the web, 3rd International Conference on Autonomous Agents.

Songa, K.-S., Hub, X., Olneyc, A. \& Graesserb, A. C. (2004) A framework of synthesizing tutoring conversation capability with web-based distance education courseware, Computers $\&$ Education, 42, 375-388.

Squires, D. (1999) Peripatetic electronic teachers in higher education, Association For Learning Technology fournal, 7, 52-63.

Tryllian (2006) Gossip agent. Available online at: http://www.tryllian.com/index_Eng.html

Walsham, G. (1993) Interpreting information systems in organizations (Chichester, John Wiley \& Sons).

Walsham, G. (1995) The emergence of interpretivism in IS research, Information Systems Research, 6, 376-394.

Yin, R. K. (1994) Case study research, design and methods (Thousand Oaks, CA, Sage).

Yin, R. K. (2003) Case study research design Eo methods (3rd edn) (Newbury Park, CA, Sage Publications). 